\title{
All Benign and Malignant Apocrine Breast Lesions Over-Express Claudin 1 and 3 and Are Negative for Claudin 4
}

\author{
Sami Shousha ${ }^{1}$ (D) Oliver Anscombe $^{1} \cdot$ Taneisha McFarlane $^{1,2}$ \\ Received: 22 June 2018 / Accepted: 8 April 2019 / Published online: 1 May 2019 \\ (C) The Author(s) 2019
}

\begin{abstract}
Invasive apocrine carcinoma of the breast is an uncommon triple negative tumour that lacks a specific therapeutic target. Apocrine metaplasia of the breast shares common morphological features with apocrine carcinoma, and was previously found to consistently over-express claudin 1 and to lack claudin 4 . This study was aimed at finding whether apocrine carcinoma, and other related apocrine breast lesions, have similar claudin profile. The immunohistochemical expression of claudin 1, 3 and 4 was studied in 11 cases of in situ and invasive apocrine breast carcinoma, 7 benign apocrine lesions and 45 consecutive morphologically non-apocrine triple negative breast carcinomas. All cases were also immunostained for Gross Cystic Disease Fluid Protein15 (GCDFP-15), a marker for apocrine differentiation. Apocrine breast lesions maintained their expression pattern from benign through DCIS to invasive carcinoma; all showing strong expression of claudin 1 and 3 and absence of claudin 4 . The same pattern of expression was seen in 2 out of the 45 morphologically non-apocrine tumours, but both showed strong positive staining for GCDFP-15. It is concluded that all benign and malignant apocrine lesions of the breast have a consistent pattern of claudin 1, 3 and 4 expression, suggesting the presence of a specific pathway for the development of invasive apocrine carcinoma. The overexpression of claudin 1 and 3 may have therapeutic implications as targets for managing apocrine cancers.
\end{abstract}

Keywords Breast · Apocrine breast carcinoma · Triple negative carcinoma $\cdot$ Claudin $1 \cdot$ Claudin $3 \cdot$ Claudin 4

\section{Introduction}

The claudins are a family of small transmembrane proteins that constitute the integral proteins of the tight junctions between epithelial cells that maintain cellular polarity, mediate permeability and are involved in signalling between the cells and their environment $[1,2]$. Most tissues or cell types express multiple claudins which are specific for a given tissue or cell [1]. Altered expression of several claudins, in particular claudin 1, 3, 4 and 7 has been linked to the development of various cancers [1], and are thought to be implicated in the metastatic process [3]. The

Part of this study was presented at the $28^{\text {th }}$ European Congress of Pathology, Cologne, Germany and published as an abstract in Virchows Archiv 2016;469 (Supp 1):S238

Sami Shousha

S.shousha@imperial.ac.uk

1 Department of Histopathology, Charing Cross Hospital and Imperial College, Fulham Palace Road, London W6 8RF, UK

2 Present address: Royal School of Mines, Imperial College, London SW7 2AZ, UK alteration can be in the form of over-expression or down regulation depending on the type of cancer [4].

In benign breast tissue, claudin 1, 3 and 4 were detected by immunohistochemistry in the membranes of the majority of normal duct cells [5]. Cells showing apocrine metaplasia were particularly positive for claudin 1 and consistently negative for claudin 4 [5]. To the best of our knowledge, claudin expression in other apocrine breast lesions has not been reported.

In breast carcinoma, down-regulation and up-regulation of the various claudins occur even in the same class of tumours [3, 5-16]. In triple negative breast carcinoma, claudin 1 has been reported to be expressed in $44.5 \%$ of cases [17], compared with 5\% in ER positive tumours [7]. Claudin 1 expression correlates with better prognosis and lower rates of recurrence and lymph node metastasis $[17,18]$. As Claudin 1 is a trans-membrane protein with 2 large extra-cellular loops, it has been suggested that it could be a candidate for use in therapeutic strategies [10].

Claudin 3 expression has been demonstrated in $79 \%$ of ER negative tumours and $89 \%$ of ER positive tumours [7]. Claudin 4 is expressed in $79 \%$ of ER negative tumours and $52 \%$ of ER positive tumours [7] and it is particularly high in 
basal-like tumours [8]. Increased claudin 4 expression is associated with poor prognosis, high tumour grade and lymph node and distal metastasis $[8,9,19]$. Claudin 4 expression was found to be inversely related to androgen receptor expression [19]. Claudin 3 and 4 are expressed in Paget's disease of the nipple [20]. Loss of expression of claudin 3 and 4 promotes epithelial-mesenchymal transition [21].

This study was aimed at investigating claudin expression in benign and malignant apocrine breast lesions and compare this with the expression in morphologically non-apocrne triple negative carcinomas as well as in a variety of non-apocrine benign breast lesions.

\section{Materials \& Methods}

A total of 129 formalin fixed, paraffin -embedded tissue samples were studied. These included 117 excision, and 12 core biopsies. The diagnosis of benign and malignant apocrine lesions was based on the characteristic eosinophilic staining of the cytoplasm and was confirmed by immunostaining for Gross Cystic Disease Fluid Protein-15 (GCDFP-15) which showed strong diffuse expression of the protein in the majority of tumour cells [22]. All 45 morphologically non-apocrine tumours were also stained for GCDFP-15. All invasive carcinomas, apocrine or non-apocrine, were ER, PgR and HER2 negative, although 2 apocrine cases showed week HER2 positivity.
Tissue blocks were obtained via the Charing Cross Hospital surgical databases (SunquestCoPathPlus ${ }^{\mathrm{TM}}$ 2007). The histopathological diagnoses of the breast tissue used are detailed in Tables 1. Ethical approval was granted by Imperial College Healthcare NHS Trust Tissue Bank on 02/08/2015, Project number R15039.

Paraffin tissue blocks were cut into $4 \mu \mathrm{m}$ sections using a Rotary Microtome H325 (Leica Biosystems ${ }^{\mathrm{TM}}$ ). A total of 4 sections were cut per tissue block and floated on water at $40{ }^{\circ} \mathrm{C}$ before being loaded onto Superfrost ${ }^{\mathrm{TM}}$ Plus IHC microscopy slides (Thermo $@$ Scientific). One slide was stained with $\mathrm{H} \& \mathrm{E}$ and 3 used for immunohistochemistry using the following antibodies: Rabbit anti claudin 1 pAb (ab15098) (Abcam $^{\mathrm{TM}}$ ), Rabbit anti claudin 3 pAb (34-1700) (LifeTechnologies ${ }^{\mathrm{TM}}$ ) and mouse anti claudin 4 mAb (32-9400) (LifeTechnologies ${ }^{\mathrm{TM}}$ ). Antibodies were prepared with Bond Primary Antibody Diluent (AR9352) (Leica Biosystems ${ }^{\mathrm{TM}}$ ). IHC was performed using a Bond Polymer Refine Detection Kit (DS9800) (Leica Biosystems ${ }^{\mathrm{TM}}$ ) of which the constituents are as follows: $4 \%$ hydrogen peroxide block $(30 \mathrm{ml})$, post primary rabbit anti mouse IgG $(<10 \mu \mathrm{g} / \mathrm{ml})$ in $10 \%$ animal serum in tris-buffered saline $(30 \mathrm{ml})$, polymer antirabbit poly-HRP-IgG in $10 \%$ animal serum $(30 \mathrm{ml})$, $66 \mathrm{mM}$ 3,3'-Diaminobenzidine tetrahydrochloride hydrate (DAB) chromogen $(62.4 \mathrm{ml})$ and haematoxylin counterstain $(30 \mathrm{ml})$.
Table 1 A list of the cases studied and the result of their claudin staining

\begin{tabular}{|c|c|c|c|c|}
\hline Diagnosis & Number of cases & Claudin 1 & Claudin 3 & Claudin 4 \\
\hline Normal & 5 & - & \pm & + \\
\hline Columnar cell change & 5 & - & \pm & - \\
\hline Usual type ductal hyperplasia & 3 & - & - & - \\
\hline Sclerosing adenosis & 1 & \pm & - & \pm \\
\hline Fibroadenoma (epithelial elements) & 5 & - & \pm & + \\
\hline Tubular adenoma & 5 & \pm & \pm & + \\
\hline Phyllodes tumour (epithelial elements) & 5 & \pm & \pm & + \\
\hline Radial scar & 2 & \pm & \pm & \pm \\
\hline Intraduct papilloma & 5 & - & \pm & + \\
\hline Flat epithelial atypia & 1 & - & + & + \\
\hline Atypical ductal hyperplasia & 2 & \pm & + & \pm \\
\hline In situ lobular neoplasia & 5 & - & - & - \\
\hline DCIS, non-apocrine & 14 & - & $-1 \pm$ & $-1 \pm$ \\
\hline Apocrine cyst & 1 & + & + & - \\
\hline Apocrine adenosis & 6 & + & + & \pm \\
\hline Apocrine DCIS & 5 & + & + & - \\
\hline Invasive apocrine carcinoma & 6 & + & + & - \\
\hline Toker Cells & 4 & - & - & - \\
\hline Paget's disease of the nipple & 4 & - & - & + \\
\hline Invasive triple negative non-apocrine carcinomas & 45 & See Table 2 & & \\
\hline
\end{tabular}

- Negative, \pm weekly positive, + strongly positive 
Table 2 Claudin staining results for invasive non-apocrine triple negative tumours

\begin{tabular}{llllr}
\hline Diagnosis & Number of cases & - & \pm & + \\
\hline Claudin 1 & 45 & $32(71 \%)$ & 7 & 6 \\
Claudin 3 & 44 & $36(82 \%)$ & 6 & 2 \\
Claudin 4 & 44 & $17(39 \%)$ & 16 & 11 \\
\hline
\end{tabular}

- Negative, \pm weekly positive, + strongly positive

Slides were heated at $60{ }^{\circ} \mathrm{C}$ for $20 \mathrm{~min}$, promoting tissue adhesion, before being deparaffinised in two changes of xylene for $5 \mathrm{~min}$ each and hydrated in 3 changes of $100 \%$ ethanol for $5 \mathrm{~min}$ each, and cold water for 5-10 min. Heatmediated antigen retrieval was achieved via steam-heating the tissues in hot citrate buffer $(10 \mathrm{mM}$ sodium citrate, $0.05 \%, \mathrm{pH} 6.0$ ) in a steam heater for $30 \mathrm{~min}$. Slides were then allowed to cool down in running water. The tissues underwent a PBS wash followed by hydrogen peroxide for $10 \mathrm{~min}$, before primary antibodies (claudin 1,3 , or 4 ) were added ( $200 \mu \mathrm{l} /$ slide) and allowed to incubate for $1 \mathrm{~h}$. The slides were then washed again with PBS and incubated with post primary antibody for $20 \mathrm{~min}$, followed by polymer for $30 \mathrm{~min}$. Visualisation of the Antibody/antigen reaction was achieved via the Bond $\mathrm{DAB}$ chromogenic detection kit and the slides were finally counterstained with hematoxylin (Leica Biosystems $^{\mathrm{TM}}$ ). Slides were cover-slipped automatically using a Leica CV5030 machine.

\section{Results (Tables 1 \& 2)}

The staining results were expressed as negative $(-)$, where no positive membrane staining was seen, weekly positive $( \pm)$ where there was faint usually localised membrane staining (similar to 1+ HER2 expression) and strongly positive (+) where there was strong membrane staining of the majority of cells (similar to $3+$ HER 2 expression).

Apocrine breast lesions maintained their expression pattern from benign through to DCIS and invasive carcinoma; all showing strong expression of claudin 1 (Fig. 1) and 3 (Fig. 2) and absence of claudin 4 (Fig. 3). This pattern was not seen in any of the non-apocrine benign or DCIS lesions, but was seen in 2 out of the 45 morphologically non-apocrine triple negative tumours. However, both tumours were GCDFP-15 strongly positive. On the other hand, three GCDFP-15 negative cases showed strong Claudin 1
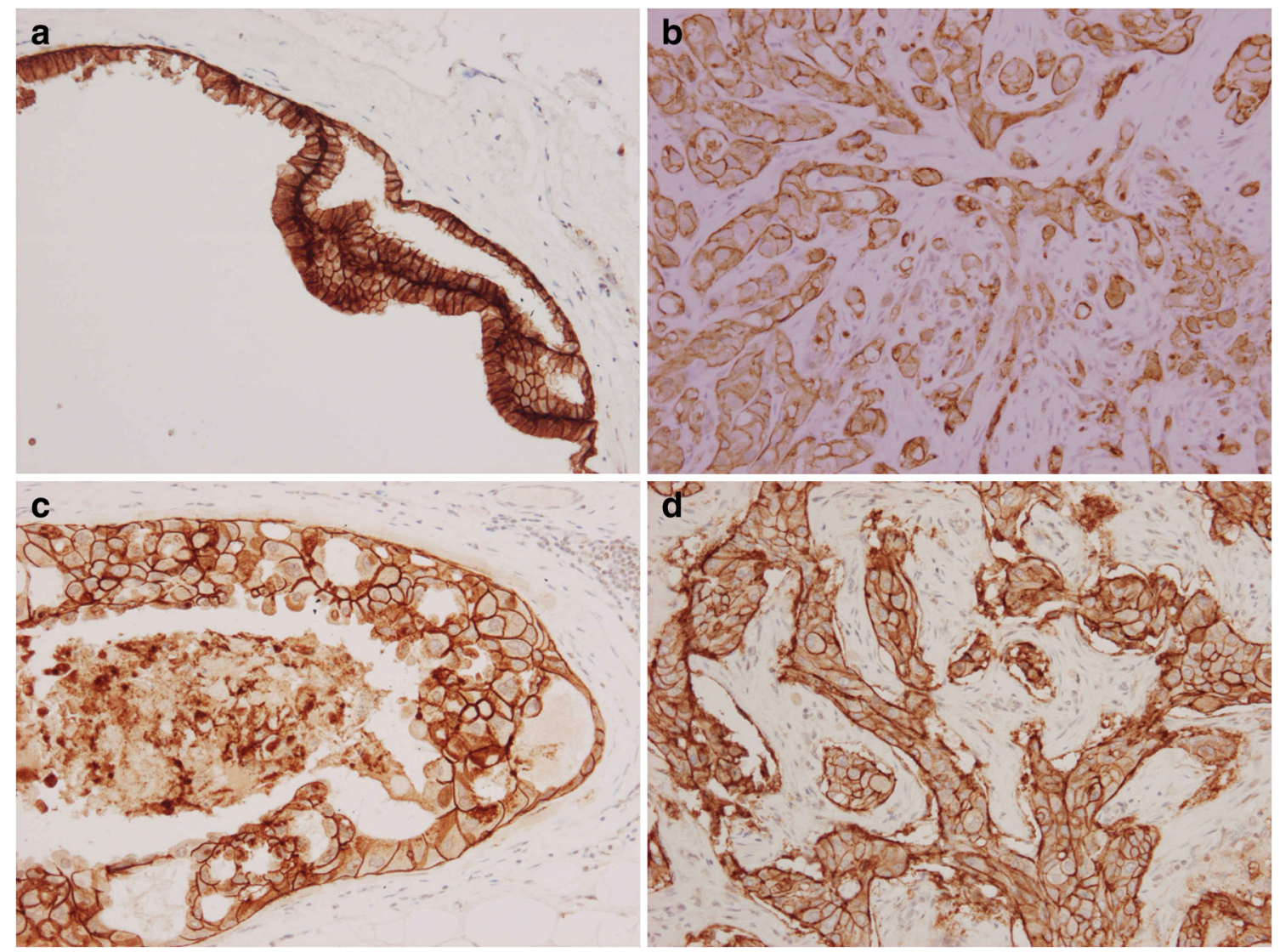

Fig. 1 Expression of claudin 1 in apocrine breast lesions: (a) Simple apocrine cyst (b) Apocrine adenosis (c) Apocrine DCIS (d) Invasive apocrine carcinoma (immunoperoxidase stain) 

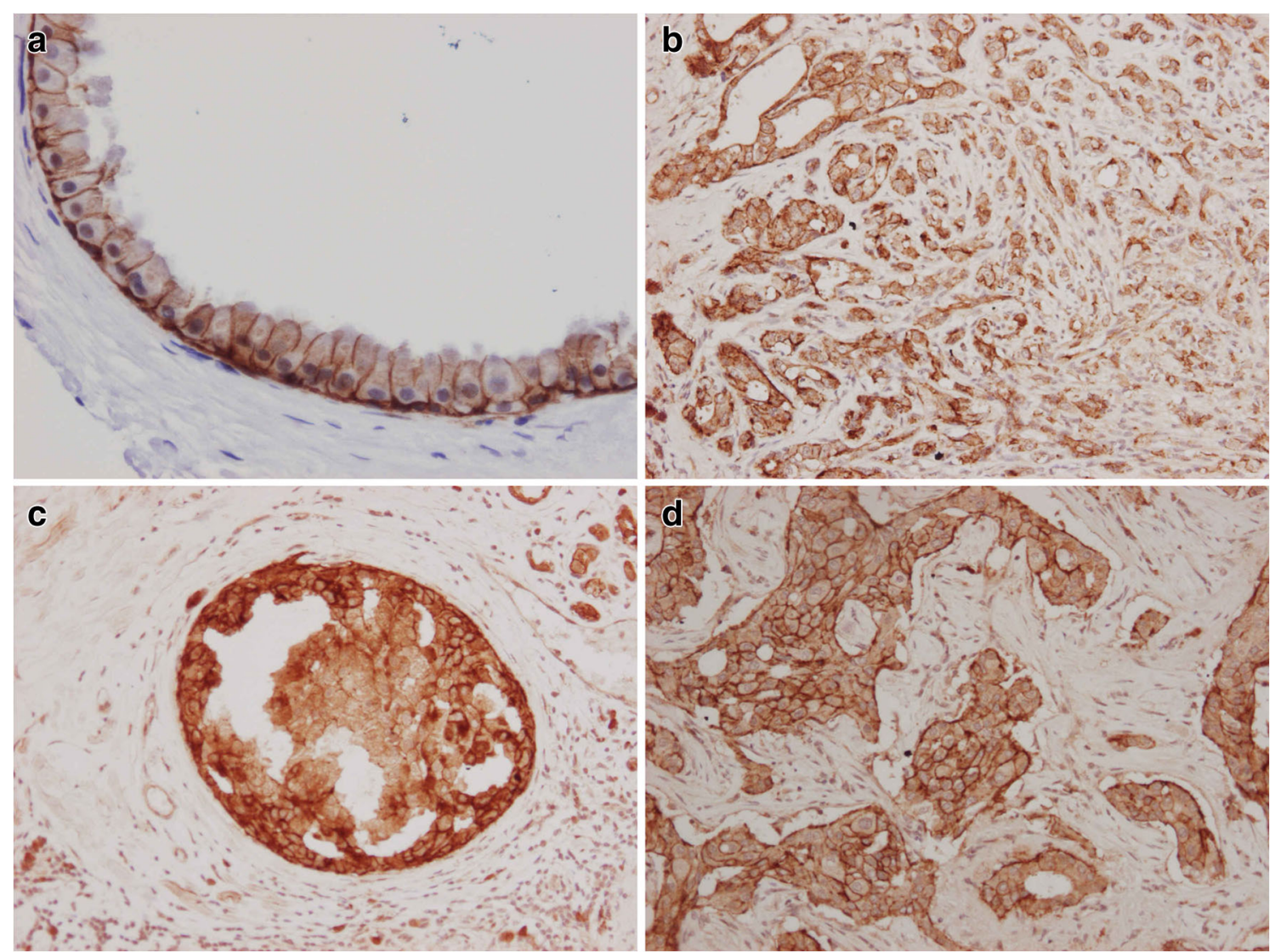

Fig. 2 Expression of claudin 3: (a) Simple apcrine cyst (b) Apocrine adenosis (c) Apocrine DCIS (d) Invasive apocrine carcinoma (immunoperoxidase stain)

positivity: one was a lympho-epithelioma-like carcinoma, the second was an invasive ductal carcinoma with abundant tumour infiltrating lymphocytes and the third had features of micropapillary carcinoma. All 3 cases were also positive for claudin 4 , and two were positive for claudin 3 . The majority of the non-apocrine triple negative tumours were negative for claudin $1(71 \%)$ and claudin $3(82 \%)$, and weakly or strongly positive for claudin 4 (61\%; Table 2). Cases of non-apocrine DCIS were negative for claudin 1 and negative or weakly positive for claudin 3 and 4 .

\section{Discussion}

To the best of our knowledge, this is the first study of claudins in a wide range of apocrine breast lesions. We found a consistent expression pattern from benign to invasive carcinoma. All cases examined including benign apocrine cysts, apocrine adenosis, apocrine DCIS and invasive apocrine carcinoma showed strong expression of claudins 1 and 3, and almost complete absence of claudin 4 . This combination was not noted in any of the other non-apocrine benign and in situ

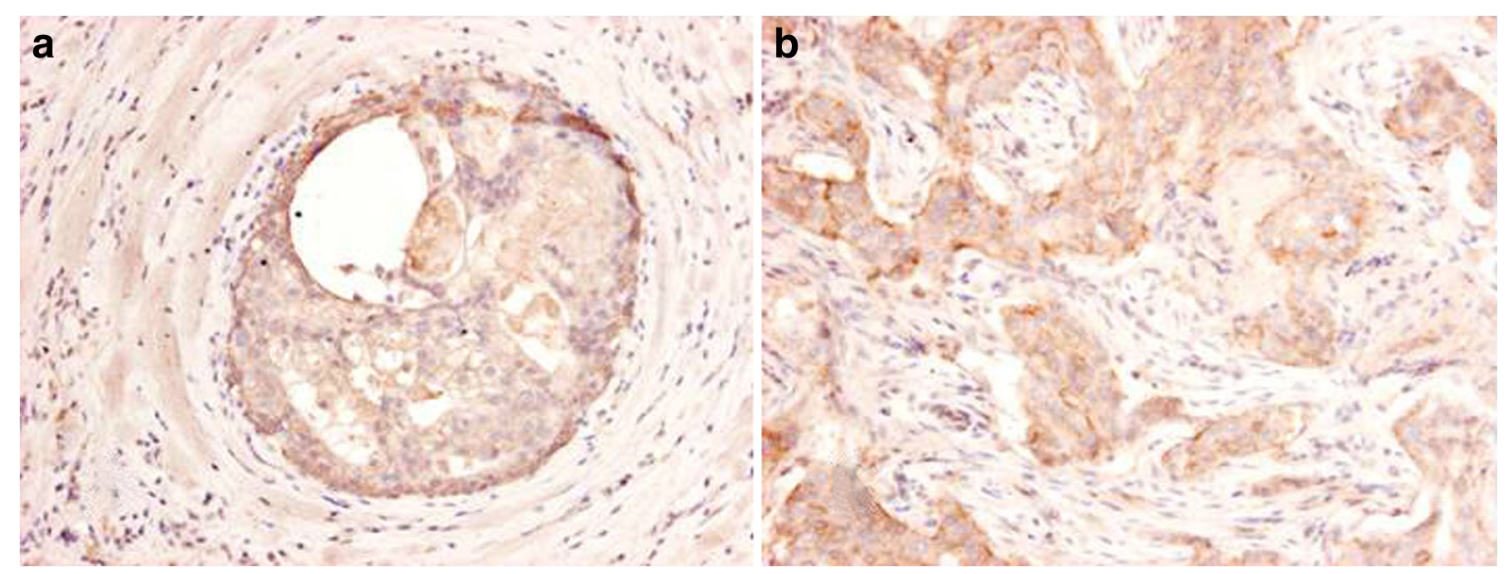

Fig. 3 Expression of claudin 4 in neoplastic apocrine breast lesions: (a) Apocrine DCIS (b) Invasive apocrine carcinoma (immunoperoxidase stain) 
neoplastic lesions examined and was only found in 2 cases of morphologically non-apocrine triple negative tumours that were GCDFP-15 strongly positive.

Invasive apocrine carcinomas are a distinct subgroup of triple negative breast carcinoma [23]. They have more favourable prognosis and low propensity to metastasise than other triple negative tumours [24]. This fact is consistent with the claudin findings in this study. Claudin 1expression has been shown to be able to exert tight junction- mediated gate function in tumour cells even in the absence of other tight junction-associated proteins [25]. Claudin 1 over-expression in breast carcinoma correlates with better prognosis and lower incidence of axillary lymph node metastasis [17, 18]; while its decreased expression is associated with higher incidence of recurrence and lymph node metastasis and short disease free interval [18]. Claudin-1 expression in non-small cell lung carcinoma is a good prognostic factor [26]. This led to the suggestion that claudin 1 may be used as a therapeutic target for tumours over-expressing it [10].

The finding of absent expression of claudin 4 in apocrine carcinoma, with its known good prognosis, is also consistent with the reported association between claudin 4 overexpression and poor prognosis and increased incidence of axillary and distant metastasis in breast carcinoma $[8,9,19]$. The finding is also consistent with the reported presence of an inverse relationship between claudin 4 and androgen receptor expression [19], as apocrine carcinomas are usually androgen receptor positive [22, 24].

The findings concerning the consistent pattern of claudin expression in all apocrine lesions of the breast, suggest the presence of a specific pathway for the development of invasive apocrine carcinoma. The over expression of claudin 1 and 3 in these triple negative tumours may be worth considering as possible therapeutic targets. In this context, affecting other benign apocrine lesions that might be present in the breast at the same time, ought not to be of concern, particularly as some of these lesions; e.g. atypical apocrine adenosis, may have a pre-cancerous potential [22].

Author Contributions SS designed the study and participated in analysing the results and writing the article. OA carried out most of the practical part of the study and participated in the analysis and writing. TM carried out the practical part of the study concerning non-apocrine carcinomas and GCDFP-15 immunostaining.

Funding Imperial College, London.

\section{Compliance with Ethical Standards}

Ethical Approval Ethical approval was granted by Imperial College Healthcare NHS Trust Tissue Bank on 02/07/2014 Project number R14056 and on 02/08/2015 Project number R15039.

Conflict of Interest None declared.
Open Access This article is distributed under the terms of the Creative Commons Attribution 4.0 International License (http:// creativecommons.org/licenses/by/4.0/), which permits unrestricted use, distribution, and reproduction in any medium, provided you give appropriate credit to the original author(s) and the source, provide a link to the Creative Commons license, and indicate if changes were made.

\section{References}

1. Kwon MJ (2013) Emerging roles of claudins in human cancer. Int J Mol Sci 14:18148-18181

2. Bleich M, Gunzel D (2017) Physiology, pathophysiology and clinical impact of claudins. Pflugers Arch 469:1-2

3. Tobaries S, Siegel PM (2016, 15 August) The role of claudins in cancer metastasis. Oncogene. https://doi.org/10.1036/onc.216.289

4. Osanai M, Takasawa A, Murata M, Sawada N (2017) Claudins in cancer. Pflugers Arch 469:55-67

5. Tokes A-M, Kulka J, Paku S, Szik A, Paska C, Novak PK et al (2005) Claudin-1. -3 and -4 proteins and mRNA expression in benign and malignant breast lesions: a research study. Breast Cancer Res 7:R296-R305. https://doi.org/10.1186/bcr983

6. Kominsky SL, Argani P, Korz D, Evron E, Raman V, Garrett E, Rein A, Sauter G, Kallioniemi OP, Sukumar S (2003) Loss of the tight junction protein claudin-7 correlates with histological grade in both ductal carcinoma in situ and invasive ductal cartcinoma of the breast. Oncogene 22:2021-2033

7. Blanchard AA, Skliris GP, Watson P, Murphy LC, Penner C, Tomes L et al (2009) Claudin 1, 3, and 4 protein expression in ER negative breast cancer correlates with markers of the basal phenotype. Virchows Arch 454:647-656

8. Kulka J, Szasz AM, Nemeth Z, Madaras L, Schaff Z, Molnar IA et al (2009) Expression of tight junction protein claudin-4 in basallike breast carcinoma. Pathol Oncol Res 15:59-64

9. Lanigan F, McKiernan E, Brennan DJ, Hegarty S, Millikan RC, McBryan J, Jirstrom K, Landberg G, Martin F, Duffy MJ, Gallagher WM (2009) Increased claudin-4 expression is associated with poor prognosis and high tumour grade in breast cancer. Int $\mathrm{J}$ Cancer 124:2088-2097

10. Myal Y, Leygue E, Blanchard AA (2010 Article ID 956897) Claudin 1 in breast tumorigenesis: Revelation of a possible novel "claudin high" subset of breast cancers. J Biomed Bioteh. https:// doi.org/10.1155/2010/956897

11. Gerhard R, Ricardo S, Albergaria A, Gomes M, Silva AR, Logullo AF, Cameselle-Teijeiro JF, Paredes J, Schmitt F (2012) Immunohistochemical features of claudin-low intrinsic subtype in metaplastic breast carcinomas. Breast 21:354-360

12. Blanchard AA, Ma X, Dueck KJ, Penner C, Cooper SC, Mulhall D, Murphy LC, Leygue E, Myal Y (2013) Cladin 1 expression in basal-like breast cancer is related to patient age. BMC Cancer 13: 268

13. Lu S, Singh K, Mangray S, Tavares R, Noble L, Resnick M et al (2013) Claudin expression in high grade invasive ductal carcinoma of the breast: correlation with the molecular type. Modern Pathol 26:485-495

14. Van Voss MRH, van Diest PJ, Smolders YHCM, Bart J, van der Wal E, van der Groep. Distinct claudin expression characterizes BRCA1=related breast cancer. Histopathology 2014;65:814-827

15. Zhou B, Moodie A, Blanchard AA, Leygue E, Myal Y (2015) Claudin 1 in breast cancer: new insights. J Clin Med 4:1960-1976

16. Dias K, Dvorkin-Gheva A, Hallett RM, Wu Y, Hassell J, Pond GR, Levine M, Whelan T, Bane AL (2017) Claudin-low breast cancer, 
clinical \& pathological characteristics. PLoS One 12:e0168669. https://doi.org/10.1371/journal.pone.0168669

17. Ma F, Ding X, Fan Y, Ying J, Zheng S, Lu N, Xu B (2014) A CLDN1-negative phenotype predicts poor prognosis in triple negative breast cancer. PLoS One 9(11):e112765

18. Morohashi S, Kusumi T, Sato F, Odagiri h $\mathrm{CH}$, Yoshihara $\mathrm{S}$ et al (2007) Decreased expression of claudin-1 correlates with recurrence status in breast cancer. Int J Mol Med 20:139-143

19. Abd-Elazeem MA, Abd-Elazeem MA (2015) Claudin 4 expression in triple negative breast cancer: correlation with androgen receptors and Ki-67 expression. Ann Diag Pathol 19:37-42

20. Soini Y (2004) Claudin 2, 3, 4 and 5 in Paget's disease and breast carcinoma. Hum Pathol 35:1531-1536

21. Lin X, Shang X, Manorek G, Howell SB (2013) Regulation of the epithelial-mesenchymal transition by claudin-3 and claudi-4. PLoS One 8(6):e67496

22. Gromov P, Espinoza JA, Gromova I (2015) Molecular and diagnostic features of apocrine breast lesions. Expert Rev Mol Diagn 15(8): 1011-1022

23. Vranic S, Merchio C, Castellano I, Botta C, Scalzo MS, Bender RP et al (2015) Immunohistochemical and molecular profiling of histologically defined apocrine carcinoma of the breast. Hum Pathol 45:1350-1359

24. Mills AM, Gottlieb CE, Wendroth SM, Brenin CM, Atkins KA (2016) Pure apocrine carcinomas represent a clinicopathologically distinct androgen receptor-positive subset of triple-negative breast cancers. Am J Surg Pathol 40:1109-1116

25. Hoevel T, Macer R, Mundigl O, Swisshelm K, Kubbies M (2002) Expression and targeting of the tight junction protein CLDN1 in CLDN1- negative human breast tumour cells. J Cell Physiol 191: 60-68

26. Moldvay J, Fabian K, Jacket M, Nemeth Z, Bogos K, Furak J et al (2017) Claudin-1 protein expression is a good prognostic factor in non-small cell lung cacer, but only in squamous cell carcinoma cases. Pathol Oncol Res 23:151-156

Publisher's Note Springer Nature remains neutral with regard to jurisdictional claims in published maps and institutional affiliations. 